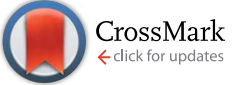

Cite this: RSC Adv., 2015, 5, 43172

Received 8th January 2015

Accepted 7th May 2015

DOI: $10.1039 / \mathrm{c} 5 \mathrm{ra00401b}$

www.rsc.org/advances

\section{A continuous method to prepare poorly crystalline silver-doped calcium phosphate ceramics with antibacterial properties}

\author{
S. Range, ${ }^{a}$ D. Hagmeyer, ${ }^{a}$ O. Rotan, ${ }^{a}$ V. Sokolova, ${ }^{a}$ J. Verheyen, ${ }^{b}$ B. Siebers ${ }^{b}$ \\ and M. Epple*a
}

\begin{abstract}
Silver-doped calcium phosphate ceramics were prepared in discontinuous and continuous processes with different amounts of incorporated silver (up to $1.8 \mathrm{wt} \%$ silver). In particular, the effects of $\mathrm{pH}$, reaction time and light exposure on the incorporation of silver into the calcium phosphate ceramic were investigated. In the dark, silver can be incorporated as colourless silver ions $\left(\mathrm{Ag}^{+}\right)$into the apatite lattice, but the integration occurs slowly. Under ambient light, a rapid photoreduction to elemental silver $\left(\mathrm{Ag}^{0}\right)$ occurs which permits a continuous process to prepare silver-doped calcium phosphate ceramics. The silver-doped calcium phosphate ceramics were characterized by scanning electron microscopy, X-ray powder diffraction, infrared spectroscopy, thermogravimetry, and elemental analysis ( $\mathrm{Ca}, \mathrm{Ag}$, phosphate). The silver release from the silver-doped calcium phosphate ceramics was measured by a combination of dialysis and atomic absorption spectroscopy. The antimicrobial effect was tested on bacteria (Escherichia coli), and the cytotoxic effect was tested on HeLa cells (human epithelial cervical cancer cells). For comparison, stoichiometric silver phosphate, $\mathrm{Ag}_{3} \mathrm{PO}_{4}$, was prepared. The release of silver from silver phosphate is much faster, leading to pronounced antibacterial but also cytotoxic effects.
\end{abstract}

\section{Introduction}

Of the most prominent calcium phosphate ceramics, hydroxyapatite (HA) is one of the most frequently used bone substitution materials, due to its similarity to the mineral in mammalian bones. $^{1-5}$ To combat infections after implantation, silver has been proposed as an antibacterial agent ${ }^{6}$ and as an additive to calcium phosphate ceramics. $^{7-25}$ This antibacterial effect has been suggested to combat bacterial colonization (i.e. biofilm formation) on implants. The properties of silver-doped calcium phosphate ceramics that are reported in the literature are diverging with respect to the chemical nature of the incorporated silver (e.g. as a calcium-substituting cation or as nanoscopic metallic silver), and the synthesis conditions are not always fully reported with respect to light exposure and reaction conditions. It was our aim to obtain a full and comprehensive picture of the different ways to prepare silver-doped calcium phosphates, employing a wide range of analytical methods. For this, the precipitation of silver-doped calcium phosphate was carried out both in a batch synthesis and in a continuous synthesis under strict control of the reaction conditions. ${ }^{26}$

${ }^{a}$ Inorganic Chemistry and Center for Nanointegration Duisburg-Essen (CeNIDE), University of Duisburg-Essen, Universitaetsstr. 5-7, 45117 Essen, Germany. E-mail: matthias.epple@uni-due.de

${ }^{b}$ Biofilm Centre Molecular Enzyme Technology and Biochemistry, University of Duisburg-Essen, Universitaetsstr. 5-7, 45117 Essen, Germany

\section{Results and discussion}

The easiest way to prepare silver-doped calcium phosphate is a batch synthesis, i.e. the precipitation of calcium phosphate in the presence of a soluble silver salt. We have systematically studied this process that depends on time, temperature and light exposure. Aqueous solutions of $\mathrm{Ca}\left(\mathrm{NO}_{3}\right)_{2},\left(\mathrm{NH}_{4}\right)_{2} \mathrm{HPO}_{4}$ and $\mathrm{AgNO}_{3}$ were mixed and stirred for different times under various conditions. The solid precipitate was isolated by centrifugation and analysed by X-ray powder diffraction, scanning electron microscopy and visual inspection.

If the batch precipitation was carried under complete light exclusion at $\mathrm{pH}$ 9, the precipitate remained white, indicating an incorporation of $\mathrm{Ag}^{+}$ions into the calcium phosphate lattice. If the $\mathrm{pH}$ was allowed to drop below 9 during the reaction, an illdefined yellow powder, consisting of poorly crystalline apatite and silver phosphate was obtained.

The integration of silver into the calcium phosphate ceramics was slow and of limited extent, pointing to a slow exchange of $\mathrm{Ca}^{2+}$ ions by $\mathrm{Ag}^{+}$ions in the dispersion (Fig. 1). Note that under these conditions, calcium phosphate rapidly precipitates and therefore a silver incorporation can only occur by ion exchange in contact of the solid with the surrounding solution. To balance the charge when one calcium ion $\mathrm{Ca}^{2+}$ is substituted by one silver ion $\mathrm{Ag}^{+}$, it is likely that one phosphate anion $\mathrm{PO}_{4}{ }^{3-}$ is protonated to a hydrogen phosphate anion $\mathrm{HPO}_{4}{ }^{2-}$, leading to a calciumdeficient hydroxyapatite CDHA. ${ }^{27,28}$ 


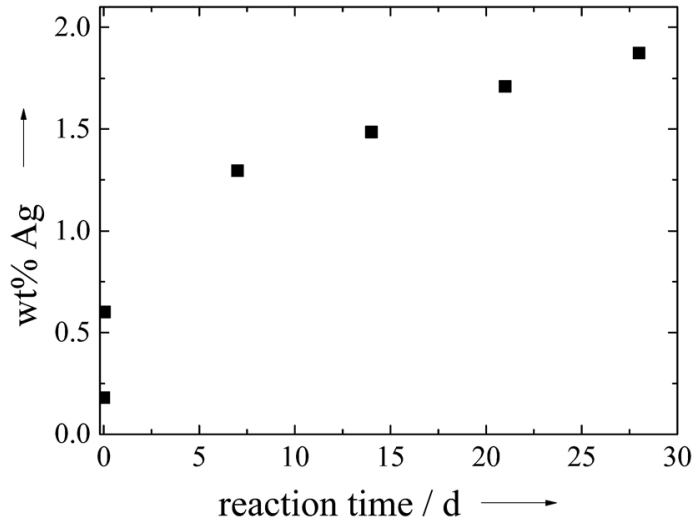

Fig. 1 Incorporation of silver into calcium phosphate ceramics as a function of the reaction time under complete light exclusion $(\mathrm{pH} 9$, molar ratio $(\mathrm{Ag}+\mathrm{Ca}) / \mathrm{P}=1.67: 1$ and molar ratio $\mathrm{Ag}: \mathrm{Ca}=1: 9)$.

If the $\mathrm{pH}$ was raised above 9 by adding ammonia, no silver incorporation was observed, even at longer times, probably due to the formation of the diammine silver complex $\left[\mathrm{Ag}\left(\mathrm{NH}_{3}\right)_{2}\right]^{+}$.

Under light exposure (daylight, no special illumination), the initially white precipitate rapidly turned grey which is an indication for the formation of metallic silver by photoreduction as ionic silver is colourless. The amount of incorporated silver increased from $0.2 \mathrm{wt} \%$ after a few seconds to $3.16 \mathrm{wt} \%$ after 3 $\mathrm{h}$. This demonstrates that reduced silver, probably as silver nanoparticles, has a much higher tendency to enter the solid calcium phosphate phase.

Due to the much faster incorporation of silver under light exposure, we developed a continuous process to obtain silverdoped calcium phosphate with a high content of silver. The experimental setup is shown in Fig. 2 .

The solid product was isolated by filtration and dried at $70^{\circ} \mathrm{C}$ in air. For comparison, pure silver phosphate, $\mathrm{Ag}_{3} \mathrm{PO}_{4}$, was prepared in the same way.

The obtained silver-doped calcium phosphate particles were small and had an irregular shape. In contrast, $\mathrm{Ag}_{3} \mathrm{PO}_{4}$ consisted of smooth, $\mu \mathrm{m}$-sized crystals (Fig. 3).

X-ray powder diffraction confirmed these observations. We found a poorly crystalline apatite phase in all cases, sometimes

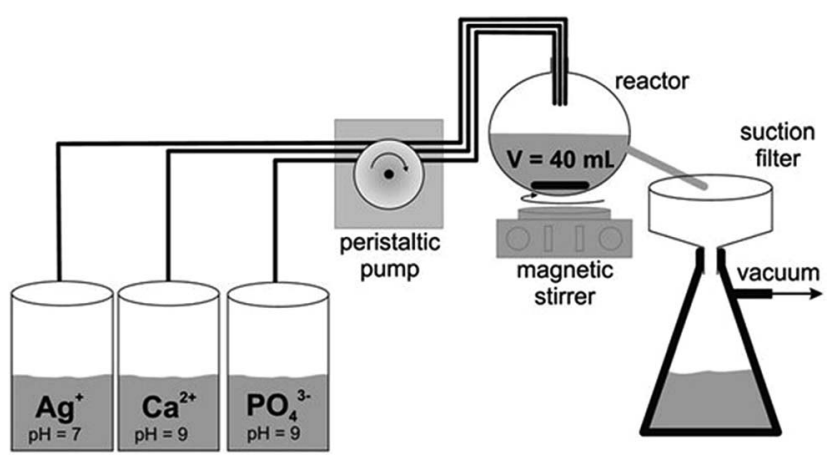

Fig. 2 Schematic setup of the continuous precipitation apparatus, used under light exposure with a residence time in the reactor of about $48 \mathrm{~s}$, followed by a residence time in the suction filter of about $30 \mathrm{~min}$.
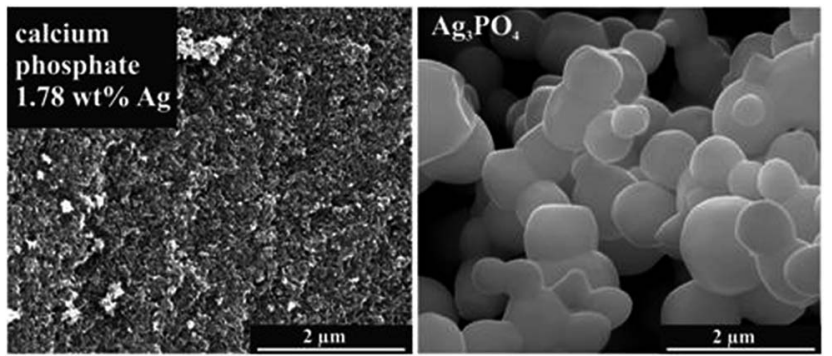

Fig. 3 SEM images of silver-doped calcium phosphate with $1.78 \mathrm{wt} \%$ silver and of pure silver phosphate.

even X-ray amorphous. The crystallinity was not significantly influenced by the presence of silver as the diffractogram of the pure calcium phosphate ceramics shows. No diffraction peaks of elemental silver or silver phosphate were detectable. This indicates that the silver is not present as a distinct phase with sufficient particle size or crystallinity. In contrast, $\mathrm{Ag}_{3} \mathrm{PO}_{4}$ showed sharp diffraction peaks, confirming the high crystallinity (Fig. 4).

Table 1 gives all analytical data for the prepared ceramics. The molar ratio of $\mathrm{Ca} / \mathrm{P}$ in the products was in the range of 1.51 to 1.60 , and the molar ratio of $(\mathrm{Ca}+\mathrm{Ag}) / \mathrm{P}$ was of the same order of magnitude. The amount of silver that was incorporated into the calcium phosphate phase was dependent on the silver concentration in solution. Between 1 and $4 \mathrm{~mol} \%$ of silver in the initial solution, silver was not detected in the calcium phosphate ceramics. Above $4 \mathrm{~mol} \%$ silver in the solution, silver was incorporated in an almost linear relationship (Fig. 5), up to 1.78 $\mathrm{wt} \%$ silver in the ceramic. Notably, the silver content in the solid ceramic was always lower than that in the solution.

We ascribe the fact that silver was not included at low concentrations to the formation of the soluble silver diammine

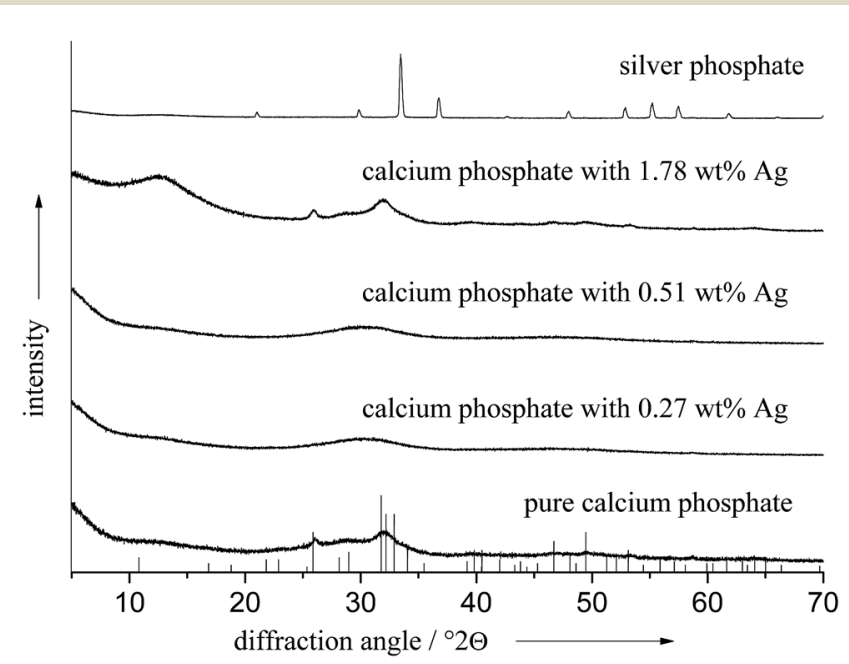

Fig. 4 X-ray powder diffraction of the silver-doped calcium phosphate ceramics with a pattern of pure hydroxyapatite (ICDD\#090432), and a powder diffraction pattern of pure silver phosphate. The intensity of all diffractograms was normalized to highest intensity, respectively. 
Table 1 Elemental analysis of the silver-doped calcium phosphate ceramics, prepared in a continuous process under light exposure at pH 9

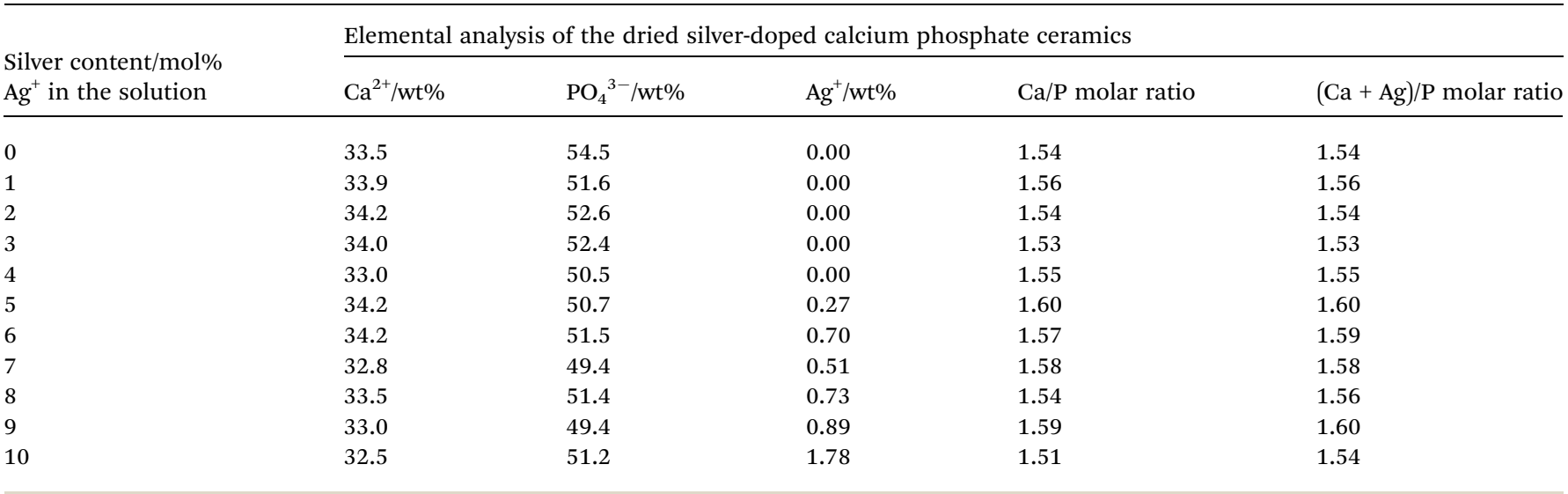

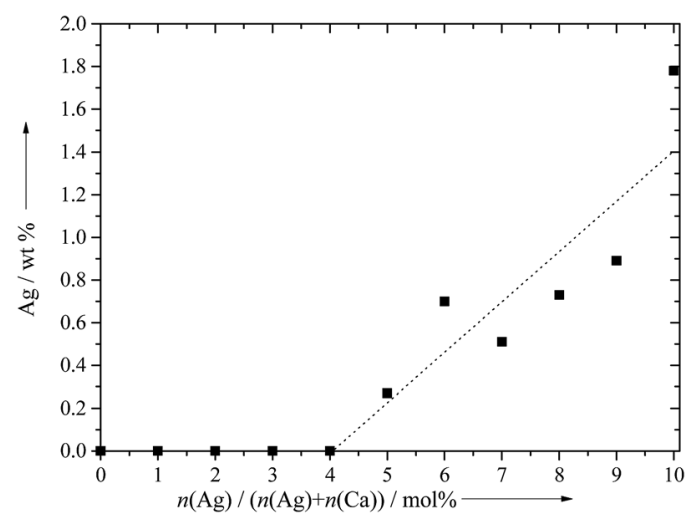

Fig. 5 The content of silver in the calcium phosphate ceramics, precipitated under light exposure at $\mathrm{pH} 9$ in a continuous process during $30 \mathrm{~min}$.

complex $\left[\mathrm{Ag}\left(\mathrm{NH}_{3}\right)_{2}\right]^{+}$. The $\mathrm{pH}$ of the calcium and phosphate solutions was adjusted to 9 with aqueous ammonia solution before the experiment. The concentration of ammonia was around $10 \mathrm{mM}$ after the dilution in the precipitation vessel.

The contents of silver and phosphate in $\mathrm{Ag}_{3} \mathrm{PO}_{4}$ were 78.6 $\mathrm{wt} \%$ and $21.4 \mathrm{wt} \%$, respectively, corresponding well to the stoichiometric values (77.3 and $22.7 \mathrm{wt} \%$ ).

In the IR spectra we observed the expected bands at 3400 $\mathrm{cm}^{-1}$ for $\mathrm{H}_{2} \mathrm{O}$, at $1625 \mathrm{~cm}^{-1}$ for the $\mathrm{OH}$ stretching vibration, at $1385 \mathrm{~cm}^{-1}$ for the carbonate stretching vibration, and at about 1040 and $560 \mathrm{~cm}^{-1}$ for the phosphate vibrations. These values are consistent with the values given in the literature. ${ }^{1,15,29-31}$ The IR spectrum of silver phosphate corresponded to the literature. ${ }^{32}$ The phosphate bands of pure $\mathrm{AgPO}_{4}$ are at $551 \mathrm{~cm}^{-1}$ and $1114 \mathrm{~cm}^{-1}$.

Thermogravimetric analysis of the silver-doped calcium phosphate ceramics gave between 9 to $13 \mathrm{wt} \%$ of water (released up to $400{ }^{\circ} \mathrm{C}$ ) and 0.5 to $0.7 \mathrm{wt} \% \mathrm{CO}_{2}$ (released from $500-700^{\circ} \mathrm{C}$ ). Note that some carbonate was incorporated into the calcium phosphate ceramics due to the precipitation in air (Fig. 6). ${ }^{26}$

The calcination of the silver-doped calcium phosphate ceramics at $850{ }^{\circ} \mathrm{C}$ led to $\beta$-tricalcium phosphate $(\beta$-TCP) with a comparable silver content. Heating to $1300{ }^{\circ} \mathrm{C}$ led to a mixture of $\alpha$ - and $\beta$-TCP with almost no silver content. Obviously, silver evaporates under these conditions (Table 2 and Fig. 6).

This indicates that it is not possible to increase the sintering temperature of such ceramics to very high temperature, e.g. to obtain a silver-doped biphasic calcium phosphate because silver evaporates $\left(T_{\text {fus }}=961.8^{\circ} \mathrm{C}\right)$.
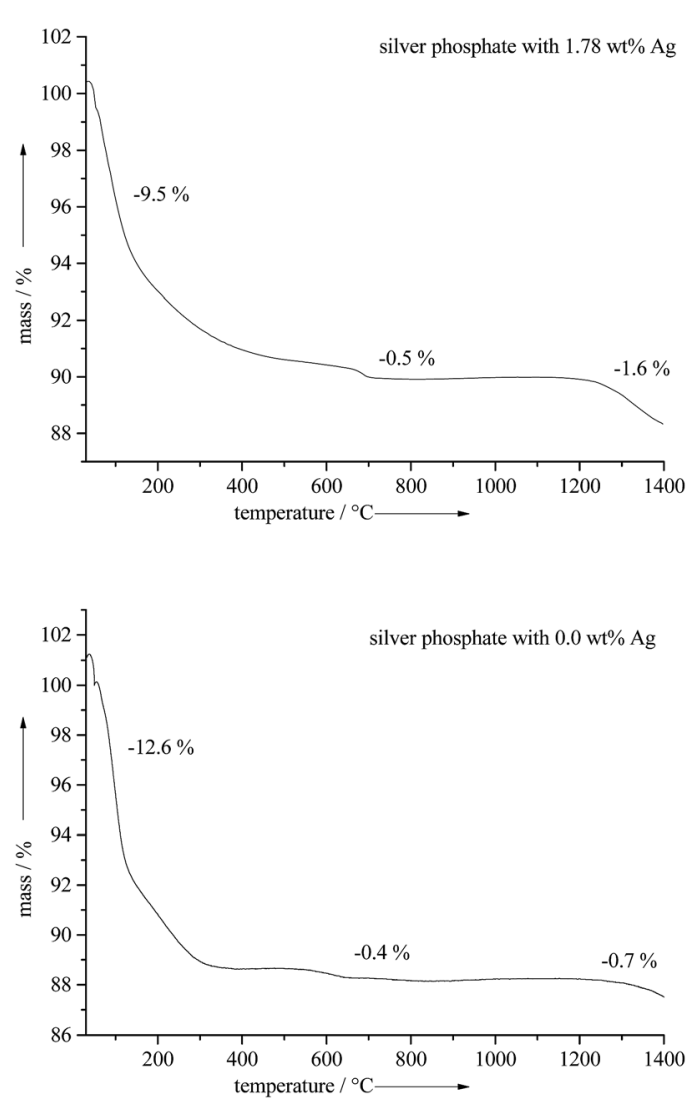

Fig. 6 Representative thermogravimetric curves for silver-doped calcium phosphate (top) and silver-free calcium phosphate (bottom). The loss of adhered and incorporated water occurred up to about $500{ }^{\circ} \mathrm{C}$, the decomposition of incorporated carbonate to carbon dioxide and calcium oxide around $700^{\circ} \mathrm{C}$, and the decomposition of apatite, including the loss of silver, above $1200^{\circ} \mathrm{C}$. 
Table 2 Elemental analysis of the silver-doped calcium phosphate ceramics (1.78 wt\% Ag), after heating to $850^{\circ} \mathrm{C}(\beta-\mathrm{TCP})$ and $1300^{\circ} \mathrm{C}$ (mixture of $\alpha$ - and $\beta$-TCP)

\begin{tabular}{llll}
\hline Temperature $/{ }^{\circ} \mathrm{C}$ & $\mathrm{Ca}^{2+} / \mathrm{wt} \%$ & $\mathrm{PO}_{4}{ }^{3-} / \mathrm{wt} \%$ & $\mathrm{Ag}^{+} / \mathrm{wt} \%$ \\
\hline 850 & 38.53 & 57.70 & 1.71 \\
1300 & 39.13 & 61.20 & 0.20
\end{tabular}

Silver ions are the biologically active component with respect to bacteria and cells. ${ }^{6}$ Therefore, a silver-doped calcium phosphate exerts its bactericidal effect through the release of silver ions. The release of silver from the silver-doped calcium phosphate ceramics samples was studied by dialysis according to ref. 33 and 34. The silver concentration remained constant after about $1000 \mathrm{~h}$ (Fig. 7).

The pellet with $1.78 \mathrm{wt} \% \mathrm{Ag}$ contained about $3.5 \mathrm{mg} \mathrm{Ag}$, of which about $130 \mu \mathrm{g}(3.7 \%)$ were released over time. The pellet with 0.88 wt $\% \mathrm{Ag}$ contained about $1.8 \mathrm{mg} \mathrm{Ag}$, of which about $20 \mu \mathrm{g}(1.1 \%)$ were released over time. As the nature of the incorporated silver (ionic substitution or metallic nanoparticle) is not quantitatively known, the release kinetics probably indicate a combination of a dissolution (ionic silver) and an oxidation (metallic silver). The pellet of $\mathrm{Ag}_{3} \mathrm{PO}_{4}$ contained about $157 \mathrm{mg} \mathrm{Ag}$, of which about $2 \mathrm{mg}$ (1.3\%) were released over time (Fig. 8). Note that silver phosphate is a sparingly water-soluble inorganic salt. ${ }^{35}$

In Fig. 9, the effect of silver-doped ceramics, $\mathrm{Ag}_{3} \mathrm{PO}_{4}$ and silver-free calcium phosphate on the Gram-negative bacterium Escherichia coli is shown. In order to reduce the dilution effect of the liquid volume, agar diffusion assays instead of liquid cultures were used, which represent established models for bacterial unsaturated biofilms at the solid/air interface and allow a qualitative analysis. The formation of inhibition zones indicates the antibacterial effect. The antibacterial effects of the pellets of silver-doped calcium phosphate and of silver phosphate were clearly visible. As expected, the pure calcium phosphate pellet showed no inhibition zone and thus no antibacterial effect.

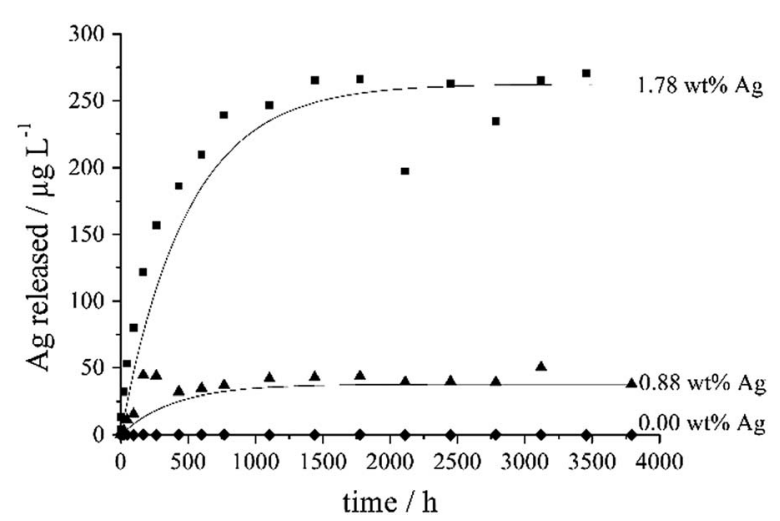

Fig. 7 Silver release from silver-doped calcium phosphate ceramic pellets $(200 \mathrm{mg})$ in contact with pure water. The liquid volume outside the dialysis tube was $0.5 \mathrm{~L}$, therefore the absolute amount of released silver was $50 \%$ of the indicated concentration in $\mu \mathrm{g}$.

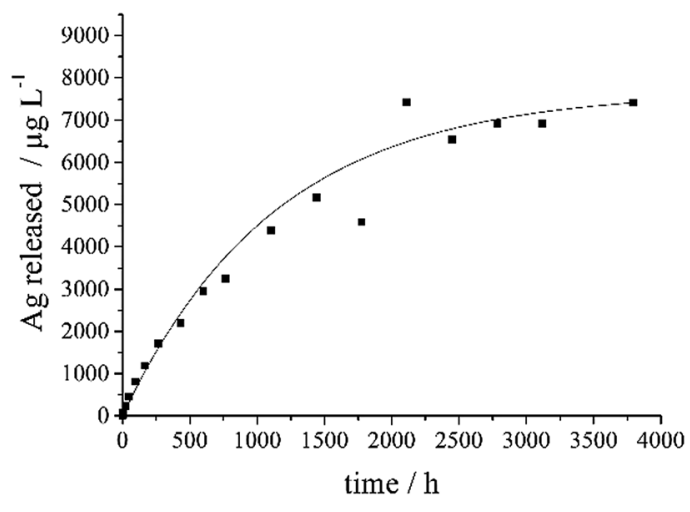

Fig. 8 Silver release from pure silver phosphate pellets $(200 \mathrm{mg})$ in contact with pure water. The liquid volume outside the dialysis tube was $0.5 \mathrm{~L}$, therefore the absolute amount of released silver was $50 \%$ of the indicated concentration in $\mu \mathrm{g}$.

The cytotoxic concentrations of ionic silver are $0.5-5 \mathrm{mg} \mathrm{L} \mathrm{L}^{-1}$ for bacteria (minimum inhibitory concentration) and 1.5-2.5 $\mathrm{mg} \mathrm{L}{ }^{-1}$ for eukaryotic cells. ${ }^{6,36}$ Except for $\mathrm{Ag}_{3} \mathrm{PO}_{4}$, these values were not reached in the dialysis experiments, but clearly, the effective silver concentration depends on the volume of the surrounding liquid. In this regard, the dialysis experiment with $500 \mathrm{~mL}$ was probably far from the conditions in the agar test.

The cell viability assays (Fig. 10) with HeLa cells showed a $100 \%$ viability after 2 and $6 \mathrm{~h}$ incubation, but a subsequent drop in cell viability (to $58 \%$ ) for silver concentrations at and above $0.89 \mathrm{wt} \% \mathrm{Ag}$. The pure calcium phosphate did not show a cytotoxicity, and in the presence of pure silver phosphate, all cells were dead after $6 \mathrm{~h}$. This illustrates the delicate interplay between a bactericidal effect and a cytotoxic effect in the case of silver. ${ }^{6}$
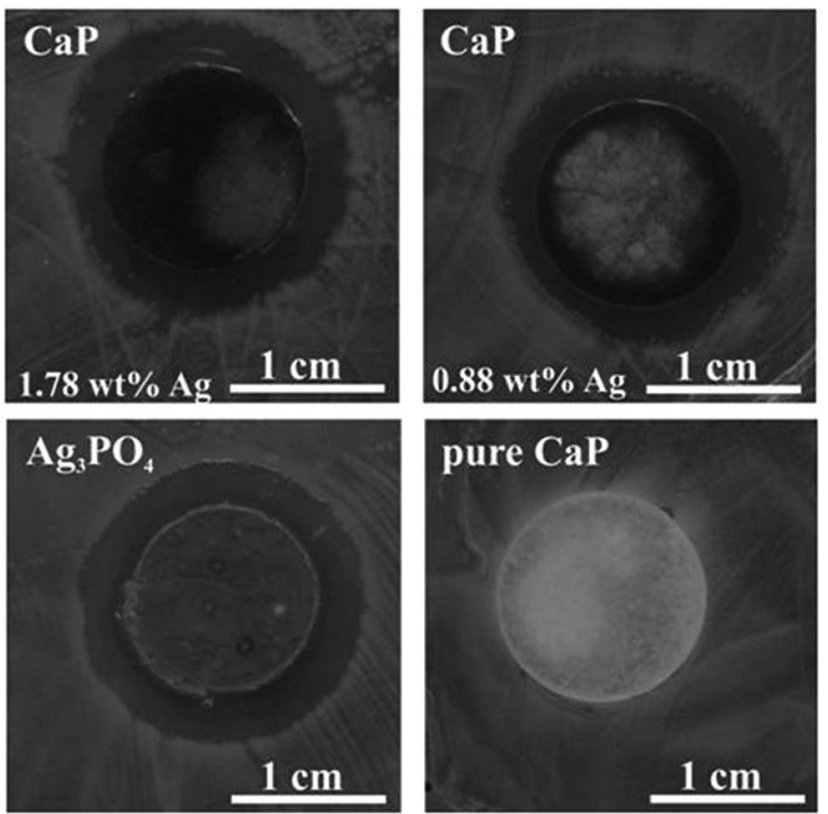

Fig. 9 Antibacterial tests with $E$. coli in the presence of calcium phosphate pellets with a silver content of $1.78 \mathrm{wt} \%$ and $0.88 \mathrm{wt} \%$ silver, pure calcium phosphate, and silver phosphate after 18 hours of incubation. 


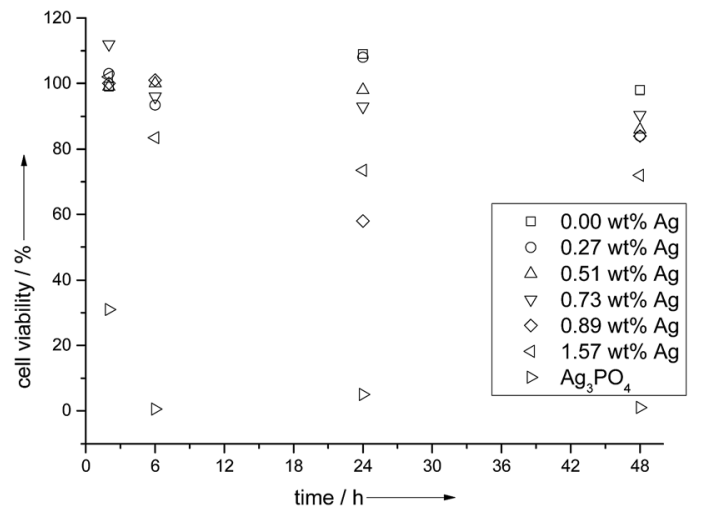

Fig. 10 Viability of HeLa cells by an MTT assay 2 h, 6 h, 24 h and 48 h after the incubation with silver-doped calcium phosphate ceramics which contained 0 wt $\%, 0.27$ wt $\%, 0.51$ wt $\%, 0.73$ wt $\%, 0.89$ wt $\%$ and $1.57 \mathrm{wt} \%$ silver.

\section{Experimental part}

A batch synthesis of silver-doped calcium phosphate was carried out by rapidly mixing solutions of $\mathrm{Ca}\left(\mathrm{NO}_{3}\right)_{2}(16.2 \mathrm{mM})$, $\left(\mathrm{NH}_{4}\right)_{2} \mathrm{HPO}_{4}(10.8 \mathrm{mM})$ and $\mathrm{AgNO}_{3}(1.8 \mathrm{mM})$ and stirring at room temperature. Aliquots of the precipitate were taken from time to time and analysed with respect to their composition.

The silver-doped calcium phosphate was precipitated in a continuous process ${ }^{26}$ by rapidly mixing equal volumes of the following aqueous solutions: 18 to $16.2 \mathrm{mmol} \mathrm{L}^{-1} \mathrm{Ca}\left(\mathrm{NO}_{3}\right)_{2}$, $10.8 \mathrm{mmol} \mathrm{L}^{-1}$ of $\left(\mathrm{NH}_{4}\right)_{2} \mathrm{HPO}_{4}$ and 0 to $1.8 \mathrm{mmol} \mathrm{L}^{-1} \mathrm{AgNO}_{3}$. All solutions were prepared in ultrapure water. The $\mathrm{pH}$ of the calcium and phosphate solutions was adjusted to 9 with aqueous $\mathrm{NH}_{3}$ solution. After mixing the solutions for $48 \mathrm{~s}$ (hydrodynamic residence time in the precipitation vessel), the precipitated silver-doped calcium phosphate were filtered (residence time in the filter about $30 \mathrm{~min}$ ) and subsequently dried at $70{ }^{\circ} \mathrm{C}$. Silver phosphate was prepared under the same conditions. For the precipitation of silver phosphate, we used 30 mmol $\mathrm{L}^{-1}$ silver nitrate and $10 \mathrm{mmol} \mathrm{L}^{-1}$ diammonium hydrogen phosphate.

Thermogravimetry was carried out with a Netzsch STA 209 TG-DTA instrument. The samples were heated with $1 \mathrm{~K} \mathrm{~min}^{-1}$

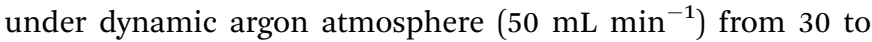
$1400{ }^{\circ} \mathrm{C}$. X-ray powder diffraction (XRD) was carried out with a Bruker D8 Advance instrument, operating with $\mathrm{Cu} \mathrm{K}_{\alpha}$ radiation $(\lambda=1.5406 \AA)$. Scanning electron microscopy was carried out with an ESEM Quanta 400 FEG (FEI) instrument on goldpalladium ( $80: 20)$-sputtered samples. Calcium and silver were determined by atomic absorption spectroscopy (AAS; Thermo Electron Corporation, M-Series AA spectrometer). Orthophosphate was determined by colorimetry with the molybdenum blue method $(\lambda=725 \mathrm{~nm})$. IR spectra were recorded in $\mathrm{KBr}$ pellets with a Bruker Vertex 70 instrument.

For the silver release experiments, cylindrical pellets weighing $200 \mathrm{mg}$ were prepared in an infrared press at $10 \mathrm{t}$ for $15 \mathrm{~min}$ (diameter $11 \mathrm{~mm}$ ). The pellets were put into a dialysis tube together with $5 \mathrm{~mL}$ ultrapure water. The external volume of the dialysis was $500 \mathrm{~mL}$. The dialysis tube had a MWCO of $10^{5} \mathrm{Da}$. The dialysis setups were kept at ambient temperature under continuous stirring with a magnetic stirrer under normal light exposure. During up to 152 days ( $3648 \mathrm{~h}$ ), aliquots of $10 \mathrm{~mL}$ were taken and analyzed by AAS.

An Escherichia coli pre-culture in late exponential growth phase was diluted 1000-fold $\left(10^{-3}\right)$ in fresh LB broth medium $(2 \%(\mathrm{w} / \mathrm{v})$, Sigma-Aldrich). $100 \mu \mathrm{L}$ of this diluted cell suspension was plated on an LB-agar plate ( $2 \%(\mathrm{w} / \mathrm{v})$ LB broth, $1.5 \%(\mathrm{w} / \mathrm{v})$ agar-agar). After 2 min incubation at room temperature, the different pellets (HA pellets with a silver content of $1.78 \mathrm{wt} \%$ and $0.88 \mathrm{wt} \%$ silver, silver phosphate and pure HA as control; weight about $200 \mathrm{mg}$ each) were applied onto the inoculated LBagar plate. The formation of inhibition zones was documented after overnight incubation of the LB-agar plates at $37^{\circ} \mathrm{C}$.

HeLa cells (human epithelial cervical cancer cells) were cultured in DMEM (Dulbecco's Modified Eagle's Medium), supplemented with $10 \%$ fetal calf serum (FCS) at $37^{\circ} \mathrm{C}$ and $10 \%$ $\mathrm{CO}_{2}$ and subcultivated according to standard cell culture protocols. $24 \mathrm{~h}$ prior to the viability assay, the cells were trypsinised and seeded in cell culture dishes with $5 \times 10^{4}$ cells per well in $0.5 \mathrm{~mL}$ DMEM with FCS.

The cell viability was analyzed by an MTT assay $2 \mathrm{~h}, 6 \mathrm{~h}, 24 \mathrm{~h}$ and $48 \mathrm{~h}$ after the incubation with silver-doped calcium phosphate ceramics (one quarter of an $11 \mathrm{~mm}$ pellet, weighing originally $200 \mathrm{mg}$ and after cutting into 4 parts weighing $50 \mathrm{mg}$, into each well) which contained $0 \mathrm{wt} \%, 0.27 \mathrm{wt} \%, 0.51 \mathrm{wt} \%, 0.73$ wt $\%, \quad 0.89$ wt $\%$ and 1.57 wt\% silver. MTT (3-(4,5dimethylthiazol-2-yl)-2,5-diphenyltetrazolium bromide; Sigma, Taufkirchen, Germany) was dissolved in PBS $\left(5 \mathrm{mg} \mathrm{mL}^{-1}\right)$ and then diluted to $1 \mathrm{mg} \mathrm{mL}^{-1}$ in the cell culture medium. The cell culture medium of the incubated cells was replaced by $300 \mu \mathrm{L}$ of the MTT solution and incubated for $1 \mathrm{~h}$ at $37{ }^{\circ} \mathrm{C}$ under $5 \% \mathrm{CO}_{2}$ in humidified atmosphere. Then, the solution of MTT was replaced by $300 \mu \mathrm{L}$ of DMSO. 30 min later, $100 \mu \mathrm{L}$ aliquots were taken for spectrophotometric analysis with a Multiscan FC instrument (Thermo Fischer Scientific, Germany) at $\lambda=570$ $\mathrm{nm}$. The absorption of incubated cells was normalized to that of control (untreated) cells, thereby indicating the relative level of cell viability.

\section{Conclusions}

A continuous synthesis for poorly crystalline silver-doped calcium phosphate ceramics at ambient temperature with different silver content and their characterisation was developed which can be easily scaled up, giving reproducible silver contents in a nanocrystalline calcium phosphate ceramic. The presence of light strongly accelerates the uptake of silver into the calcium phosphate ceramics, leading to an in situ photoreduction to elemental silver, probably in the form of very small nanoparticles that were not detectable by X-ray diffraction. In all cases, a poorly crystalline apatite is obtained without peaks for silver phosphate or any other silver-containing crystalline phases. Antimicrobial studies with E. coli show a clear antimicrobial effect of pelleted samples. The silver-doped calcium phosphate ceramics do not show a significant effect of the viability of HeLa 
cells after $24 \mathrm{~h}$ below a silver concentration of $0.89 \mathrm{wt} \%$. In contrast, stoichiometric silver phosphate has a high bactericidal effect due to a high release rate of silver ions, but this leads to a cytotoxic effect to eukaryotic cells as well, making silver phosphate unsuitable as a silver-containing ceramic material.

In conclusion, the incorporation of silver into calcium phosphate ceramics has a potential to create a bactericidal biomaterial, but the incorporation of silver must be strictly controlled during the synthesis as this influences the silver release kinetics, and silver is also toxic to eukaryotic cells at higher concentrations.

\section{Acknowledgements}

We thank the Mercator foundation for support with a Mercur startup grant (to B.S. and M.E.).

\section{Notes and references}

1 S. V. Dorozhkin and M. Epple, Angew. Chem., Int. Ed., 2002, 41, 3130-3146.

2 M. Bohner, Mater. Today, 2010, 13, 24-30.

3 D. Arcos, A. R. Boccaccini, M. Bohner, A. Diez-Perez, M. Epple, E. Gomez-Barrena, A. Herrera, J. A. Planell, L. Rodriguez-Manas and M. Vallet-Regi, Acta Biomater., 2014, 10, 1793-1805.

4 S. Weiner and H. D. Wagner, Annu. Rev. Mater. Sci., 1998, 28, 271-298.

5 J. W. C. Dunlop and P. Fratzl, Annu. Rev. Mater. Sci., 2010, 40, 1-24.

6 S. Chernousova and M. Epple, Angew. Chem., Int. Ed., 2013, 52, 1636-1653.

7 A. Peetsch, C. Greulich, D. Braun, C. Stroetges, H. Rehage, B. Siebers, M. Koeller and M. Epple, Colloids Surf., B, 2013, 102, 724-729.

8 K. S. Hwang, S. Hwangbo and J. T. Kim, J. Nanopart. Res., 2008, 10, 1337-1341.

9 Y. Zhang, Q. S. Yin, C. S. Zhou, H. Xia, Y. Zhang and Y. P. Jiao, J. Mater. Sci.: Mater. Med., 2014, 25, 801-812.

10 D. S. Syromotina, M. A. Surmeneva, S. N. Gorodzha, V. F. Pichugin, A. A. Ivanova, I. Y. Grubova, K. S. Kravchuk, K. V. Gogolinskii, O. Prymak, M. Epple and R. A. Surmenev, Russ. Phys. J., 2014, 56, 1198-1205.

11 A. Rajendran, R. C. Barik, D. Natarajan, M. S. Kiran and D. K. Pattanayak, Ceram. Int., 2014, 40, 10831-10838.

12 S. Jadalannagari, K. Deshmukh, S. R. Ramanan and M. Kowshik, Appl. Nanosci., 2014, 4, 133-141.

13 A. Dubnika and V. Zalite, Ceram. Int., 2014, 40, 9923-9930.

14 G. Ciobanu, S. Ilisei and C. Luca, Mater. Sci. Eng., C, 2014, 35, 36-42.
15 P. N. Lim, E. Y. Teo, B. Ho, B. Y. Tay and E. S. Thian, J. Biomed. Mater. Res., Part A, 2013, 101, 2456-2464.

16 C. Ciobanu, S. Iconaru, P. Le Coustumer, L. Constantin and D. Predoi, Nanoscale Res. Lett., 2012, 7, 324.

17 A. Ewald, D. Hösel, S. Patel, L. M. Grover, J. E. Barralet and U. Gbureck, Acta Biomater., 2011, 7, 4064-4070.

18 M. Díaz, F. Barba, M. Miranda, F. Guitián, R. Torrecillas and J. S. Moya, J. Nanomater., 2009, 2009, 1-6.

19 J. R. J. Delben, O. M. Pimentel, M. B. Coelho, P. D. Candelorio, L. N. Furini, F. Alencar dos Santos, F. S. de Vicente and A. A. S. T. Delben, J. Therm. Anal. Calorim., 2009, 97, 433-436.

20 L. Yang, X. Ning, Q. Xiao, K. Chen and H. Zhou, J. Biomed. Mater. Res., Part B, 2007, 81, 50-56.

21 N. Rameshbabu, T. S. Sampath Kumar, T. G. Prabhakar, V. S. Sastry, K. V. G. K. Murty and K. Prasad Rao, J. Biomed. Mater. Res., Part A, 2007, 80, 581-591.

22 W. Chen, S. Oh, A. P. Ong, N. Oh, Y. Liu, H. S. Courtney, M. Appleford and J. L. Ong, J. Biomed. Mater. Res., Part A, 2007, 82, 899-906.

23 S. K. Arumugam, T. P. Sastry, B. Sreedhar and A. B. Mandal, J. Biomed. Mater. Res., Part A, 2007, 80, 391-398.

24 S. M. F. Asmus, S. Sakakura and G. Pezzotti, J. Compos. Mater., 2003, 37, 2117-2129.

25 X. Zhang, G. H. M. Gubbels, R. A. Terpstra and R. Metselaar, J. Mater. Sci., 1997, 32, 235-243.

26 D. Tadic, F. Peters and M. Epple, Biomaterials, 2002, 23, 2553-2559.

27 C. S. Liu, Y. Huang, W. Shen and J. H. Cui, Biomaterials, 2001, 22, 301-306.

28 Z. Zyman, A. Goncharenko, D. Rokhmistrov and M. Epple, Materialwiss. Werkstofftech., 2011, 42, 154-157.

29 L. Badrour, A. Sadel, M. Zahir, L. Kimakh and A. El Hajbi, Annales de Chimie Science des Matériaux, 1998, 23, 61-64.

30 D. Tadic and M. Epple, Biomaterials, 2004, 25, 987-994.

31 H. Yang, B. Xiao and K. W. Xu, J. Mater. Sci.: Mater. Med., 2009, 20, 785-792.

32 M. Thomas, S. K. Ghosh and K. C. George, Mater. Lett., 2002, 56, 386-392.

33 K. Loza, J. Diendorf, C. Greulich, L. Ruiz-Gonzales, J. M. Gonzalez-Calbet, M. Vallet-Regi, M. Koeller and M. Epple, J. Mater. Chem. B, 2014, 2, 1634-1643.

34 S. Kittler, C. Greulich, J. Diendorf, M. Köller and M. Epple, Chem. Mater., 2010, 22, 4548-4554.

35 D. R. Lide, CRC Handbook of Chemistry and Physics, Internet Version, 2005.

36 C. Greulich, D. Braun, A. Peetsch, J. Diendorf, B. Siebers, M. Epple and M. Koller, RSC Adv., 2012, 2, 6981-6987. 